\title{
Laboratory investigation of a new scale inhibitor for preventing calcium carbonate precipitation in oil reservoirs and production equipment
}

\author{
Azizollah Khormali ${ }^{1}$ Dmitry G. Petrakov ${ }^{1}$
}

Received: 15 January 2015/Published online: 23 April 2016

(c) The Author(s) 2016. This article is published with open access at Springerlink.com

\begin{abstract}
The formation of mineral scale is a complex problem during the oilfield operations. Scale inhibitors are widely used to prevent salt precipitation within reservoirs, in downhole equipment, and in production facilities. The scale inhibitors not only must have high effectiveness to prevent scale formation, but also have good adsorptiondesorption characteristics, which determine the operation duration of the scale inhibitors. This work is focused on the development of a new scale inhibitor for preventing calcium carbonate formation in three different synthetic formation waters. Scale inhibition efficiency, optical density of the solution, induction time of calcium carbonate formation, corrosion activity, and adsorption-desorption ability were investigated for the developed scale inhibitor. The optimum concentration of hydrochloric acid in the inhibitor was determined by surface tension measurement on the boundary layer between oil and the aqueous scale inhibitor solution. The results show that the optimum mass percentage of $5 \%$ hydrochloric acid solution in the inhibitor was in the range of $8 \%$ to $10 \%$. The new scale inhibitor had high efficiency at a concentration of $30 \mathrm{mg} / \mathrm{L}$. The results indicate that the induction period for calcium carbonate nucleation in the presence of the new inhibitor was about 3.5 times longer than the value in the absence of the inhibitors. During the desorption process at reservoir conditions, the number of pore volumes injected into the
\end{abstract}

Azizollah Khormali

aziz.khormaly.put@gmail.com; khormali@spmi.ru

1 Department of Oil and Gas Field Development and Operation, Oil and Gas Faculty, National Mineral Resources University (Mining University), Saint Petersburg, Russia 199106

Edited by Yan-Hua Sun carbonate core for the developed inhibitor was significantly greater than the volume of a tested industrial inhibitor, showing better adsorption/desorption capacity.

Keywords Scale inhibitor - Desorption - Corrosion activity $\cdot$ Precipitation $\cdot$ Optical density

\section{Introduction}

Huge amounts of water are injected into reservoirs to maintain the reservoir pressure at the required level, whereby salt deposition occurs as a result of water combination (Fan et al. 2012). As the reservoirs continue to deplete and more and more wells are experiencing increasing high water cut, the scaling problem is aggravated. Besides, there is a need for withdrawal of residual oil, requiring the use of modern technologies to improve oil recovery, including physical and chemical methods, which also stimulate the deposition of salts (Demadis et al. 2007; Awan and Al-Khaledi 2014). The dynamics of gas-liquid mixtures in wellbores, degassing, and various flow rates, which are determined by the flow rate of wells and the construction of the lifting equipment, affect the balance of a salt solution. Therefore, precipitation of salts can occur. This can be promoted by ingress of mechanical impurities, corrosion products as crystallization centers, various chemical treatments, and other mechanisms (Al-Tammar et al. 2014). The main reasons for deposition of salts are the changing of pressure-temperature conditions in the process of production and the incompatibility of injection water and formation water. Salt precipitation can damage the formation by permeability reduction (Moghadasi et al. 2004).

Inorganic salts may be deposited on the inner surface of the oilfield equipment during production. Salt precipitation 
occurs in all operations of wells, but the most negative consequences of scaling occur during oil production using electric submersible pumps (ESPs) (Poynton et al. 2008; Chen et al. 2013). Intense deposition of calcium carbonate on impellers of ESPs results from an increase in the produced fluid temperature, which is caused by the heat generated by the operating submersible motor. Along with salt deposition in wells, intense salt precipitation is observed in the wellhead, oil pipeline gathering, metering devices, facilities for the preparation of oil, and in reservoirs in waterflooding operations (Mackay 2005).

The process of precipitation of calcium carbonate occurs in three stages. In the first step, calcium ions combine with carbonate ions to form calcium carbonate $\left(\mathrm{CaCO}_{3}\right)$ microparticles. Next, $\mathrm{CaCO}_{3}$ particles combine in microcrystals that serve as crystallization centers for the remainder of the solution. Crystal aggregates grow and precipitate or attach to the walls of the equipment at certain sizes (Tomson et al. 2003; El-Said et al. 2009; Kelland 2011). Calcium carbonate is found in the form of white crystals. The main factor influencing the formation of carbonate deposits is that the formation water must be supersaturated with calcium, carbonate, or bicarbonate ions (Kumar et al. 2010; Bezerra et al. 2013; Mavredaki and Neville 2014). More, inorganic calcium carbonate precipitates from the supersaturated solution of salts as a result of changes in temperature and pressure during oil-water flow in the wellbore. Temperature and pressure have a great effect on $\mathrm{CaCO}_{3}$ formation and precipitation. An increase in temperature causes the outgassing of $\mathrm{CO}_{2}$ contained in water, raising the $\mathrm{pH}$, and this provokes the calcium carbonate precipitation.

All scaling control technology is divided into either prevention or removal of scaling. Chemical methods for preventing scale formation by use of scale inhibitors are more effective than other possible methods (Lakshmi et al. 2013). Basic technologies of inhibitor injection are divided as follows: reagent delivery into the wellbore and into the formation. Delivery into the wellbore is carried out by means of a dosing pump at the surface, into a given point along the well and the periodic injection into the annulus through aggregators. Scale inhibitor delivery into the formation is done through squeeze treatments via injection wells (in the pressure maintenance system), injection of the inhibitor with the fracturing fluid during fracturing (ScaleFrac), or addition of the inhibitor to the proppant (ScaleProp) (Levanyuk et al. 2012; Khormali and Petrakov 2014).

In this paper, the ongoing development of a new scale inhibitor for preventing calcium carbonate deposition during the production from oil wells is explained and a range of experimental work is described to evaluate the new inhibitor.

\section{Experimental}

In this study, the following experimental work has been carried out:

- Optimization of the hydrochloric acid $(\mathrm{HCl})$ concentration in the developed scale inhibitor by measuring surface tension on the boundary layer between the oil and the aqueous scale inhibitor solution.

- Jar test (static test for scale inhibition efficiency).

- Compatibility of the scale inhibitors with formation waters.

- Change in absorbance of the aqueous scale inhibitor solution.

- Improvement in induction time of calcium carbonate formation in presence of scale inhibitors.

- Corrosiveness of the scale inhibitors.

- Investigation of adsorption-desorption properties of the scale inhibitors in real core samples.

\subsection{Experimental materials}

\subsubsection{Synthetic formation waters}

Three different synthetic formation waters, the ionic composition of which is similar to actual formation waters, are shown in Table 1. Table 1 indicates that the synthetic waters had high concentrations of bicarbonate, carbonate, and calcium ions, which are the main factors of $\mathrm{CaCO}_{3}$ precipitation in water because the formation water must be supersaturated with these ions to precipitate this salt (Chen et al. 2005). The ions were contained in the formation waters in various concentrations and ratios of their mutual concentrations.

There are different formation water classification systems. Sulin's system, among other systems, is more descriptive of petroleum formation waters (Ostroff 1967). According to the Sulin's system, all the synthetic formation waters are a calcium chloride type.

\subsubsection{Preparation of aqueous scale inhibitor solution}

The following chemical reagents were used as the scale inhibitor components in the developed inhibitor: 1-hydroxyethane-1, 1-diphosphonic acid (HEDP), ammonium chloride, hydrochloric acid, isopropyl alcohol, polyethylene polyamine- $N$-methylphosphonic acid, and water. In addition, an industrial scale inhibitor, which is based on compounds of phosphorus, was used to compare with the developed inhibitor.

The aqueous scale inhibitor solution was prepared by dissolving the chemical reagents at different mass 
Table 1 Characteristics of synthetic formation waters

\begin{tabular}{|c|c|c|c|c|c|c|c|c|c|c|}
\hline \multirow{2}{*}{$\begin{array}{l}\text { Synthetic } \\
\text { Formation } \\
\text { water }\end{array}$} & \multirow[t]{2}{*}{$\mathrm{pH}$} & \multirow[t]{2}{*}{ Density, $\mathrm{mg} / \mathrm{m}^{3}$} & \multicolumn{7}{|c|}{ Ion content, $\mathrm{mg} / \mathrm{L}$} & \multirow{2}{*}{$\begin{array}{l}\text { Total dissolved } \\
\text { salts, } \mathrm{mg} / \mathrm{L}\end{array}$} \\
\hline & & & $\mathrm{HCO}_{3}{ }^{-}$ & $\mathrm{CO}_{3}{ }^{2-}$ & $\mathrm{Cl}^{-}$ & $\mathrm{Ca}^{2+}$ & $\mathrm{Mg}^{2+}$ & $\mathrm{Na}^{+}$ & $\mathrm{K}^{+}$ & \\
\hline 1 & 6.92 & $1012 \mathrm{E}+06$ & 9654 & 895 & 11,840 & 17,194 & 3489 & 10,753 & 647 & 54,470 \\
\hline 2 & 7.34 & $1023 \mathrm{E}+06$ & 1633 & 1547 & 30,558 & 21,469 & 5287 & 17,347 & 518 & 93,080 \\
\hline 3 & 7.13 & $1018 \mathrm{E}+06$ & 22,784 & 7871 & 34,772 & 19,836 & 4173 & 33,248 & 972 & 123,660 \\
\hline
\end{tabular}

concentrations. Distilled water was used to prepare chemical solutions of scale inhibitor in laboratory experiments. This was done to eliminate the influence on properties of the composition and the results of experiments of ion determination. Medical syringes and high precision laboratory balances were used for the exact values of the reagents masses. This ensures the precision of the required volume of the composition, as well as the precision of concentrations of components, in the preparation of the aqueous scale inhibitor solution.

\subsection{Experimental methods}

\subsubsection{Scale inhibitor performance measurement}

The effectiveness of the inhibitor can be evaluated by its effect on real formation water or synthetic formation water. However, the use of synthetic formation water provides a more comprehensive assessment for a specific type of salt (Matty and Tomson 1988; Tortolano et al. 2014). The effectiveness of an inhibitor was evaluated by the mass change of precipitates, which were formed in mineralized water in the presence of inhibitor with respect to water with no inhibitor (Drela et al. 1998). The protective effect of an inhibitor is calculated by the following equation:

$E=\frac{m_{0}-m}{m_{0}} \times 100 \%$,

where $E$ is the scale inhibitor efficiency; $m$ and $m_{0}$ are the mass of salt precipitates in water with and without inhibitor, respectively, mg.

Working solutions were prepared for studying the spontaneous process of $\mathrm{CaCO}_{3}$ precipitation in the aqueous solutions. $\mathrm{CaCl}_{2}$ solutions of different concentrations have been used in the experiments. Throughout the experiment, the solutions were mixed constantly with a magnetic stirrer.

To determine the efficiency of the scale inhibitors, two narrow neck flasks of $200 \mathrm{~mL}$ were used. The first flask consisted of formation water without inhibitor, and the second consisted of formation water with $30 \mathrm{mg} / \mathrm{L}$ scale inhibitor. The flasks were closed by a lid and heated to $80{ }^{\circ} \mathrm{C}$. Then, the solutions were filtered through a $0.45-\mu \mathrm{m}$ filter paper. The weight of crystals on the filter paper was measured.

\subsubsection{Optical density of the inhibitor solution and induction period of $\mathrm{CaCO}_{3}$}

The developed inhibitor was evaluated by determining the residual content of scale inhibitors in liquid samples. For this purpose, the concentration of the developed inhibitor in the formation water was determined based on the reaction of the ions with molybdate in an acid medium (MacAdam and Parsons 2004). The absorbance (optical density) of the obtained solutions was measured with a photo colorimeter at a wavelength $\lambda=540 \mathrm{~nm}$ because the most frequent absorbance of the inhibitor occurred at this wavelength. It was done in cells with a layer thickness of $30 \mathrm{~mm}$ at different concentrations of the developed scale inhibitor. The optical density should not exceed one. A control sample was taken as a standard solution. Optical density is defined as the logarithmic ratio of the intensity of the incident light to the intensity of the transmitted light through the aqueous scale inhibitor solution.

Induction time is a major factor in studying the prevention of the deposition of inorganic salts. The induction time was determined by measuring the changes in the intensity of the transmitted light through the formation waters with and without the scale inhibitor. For this purpose, a laser analyzer was used to analyze the microparticle size distribution. In addition, a photoelectric nephelometerabsorptiometer was used to obtain curves, which show the dependency of the light absorption on the testing time. The period, at which the light absorption is constant, displays the induction time of the salt formation.

\subsubsection{Corrosion rate of the scale inhibitor}

The corrosion activity of the inhibitors was evaluated by the gravimetric method-by measuring weight loss of the metal samples (with dimensions of $1.92 \mathrm{~cm} \times 1 \mathrm{~cm} \times$ $0.2 \mathrm{~cm}$ length, width, and thickness, respectively) before and after soaking in the aqueous inhibitor solution for $72 \mathrm{~h}$ at $80{ }^{\circ} \mathrm{C}$. The corrosion rate of samples (density of the steel 
samples is $7821 \mathrm{~kg} / \mathrm{m}^{3}$ ) is calculated as follows (Osokogwu and Oghenekaro 2012):

$v_{\mathrm{c}}=1.12 \times 10^{-3} \times \frac{m_{1}-m_{2}}{S t}$,

where $v_{\mathrm{c}}$ is the corrosion rate of the used metal sample, $\mathrm{mm} /$ year; $m_{1}$ and $m_{2}$ are the mass of the metal sample before and after the corrosion test, respectively, $\mathrm{mg} ; S$ is the surface area of the metal sample, $\mathrm{m}^{2}$; and $t$ the test time, $\mathrm{h}$.

\subsubsection{Adsorption-desorption properties of the scale inhibitor under dynamic conditions}

The adsorption and desorption ability of the inhibitors was studied by injecting aqueous scale inhibitor solution into the core samples. Figure 1 illustrates an apparatus for injecting formation waters and the aqueous scale inhibitor solution into the core samples at desired reservoir conditions. This apparatus is composed of a core holder, a pressure transducer, dosing pumps for injecting formation waters and inhibitors into the core samples, an oven, a vacuum pump, and a brine collection tank.

The adsorption-desorption characteristics of the scale inhibitors and the volume of the scale inhibitors or formation water injected were evaluated in the core samples using this apparatus. Therefore, a relative concentration of the inhibitor solution at the core outlet during adsorption and desorption processes was measured at different injection volumes. The relative concentration of the inhibitor was defined as a ratio of the inhibitor concentrations after and before injecting the inhibitor solution into the core samples.

The volume of the solution injected is defined as follows:
$V_{\mathrm{inj}}=100 \times \frac{Q t}{L A \phi}$,

where $V_{\text {inj }}$ is the volume of the solution injected into the core sample, $\mathrm{PV}$ (pore volume of the core sample); $Q$ is the volumetric flow rate of the injected solution, $\mathrm{m}^{3} / \mathrm{h} ; t$ is the time, $\mathrm{h} ; L$ is the length of the core sample, $\mathrm{m} ; A$ is the cross-sectional areas of the core sample, $\mathrm{m}^{2}$; and $\phi$ is the porosity, $\%$.

The tests were performed at $80{ }^{\circ} \mathrm{C}$ in an open system with a jacketed crystallizer; the exposure time was $72 \mathrm{~h}$. During the tests, a pressure of 8.1 MPa and concentration of $30 \mathrm{mg} / \mathrm{L}$ of scale inhibitors were applied. The $\mathrm{pH}$ value of the system was 6.9 . The flow rate was $0.0006 \mathrm{~m}^{3} / \mathrm{h}$. The core samples used had an average porosity of $20 \%$, a length of $0.035 \mathrm{~m}$, a cross-sectional area of $0.000625 \mathrm{~m}^{2}$, and a permeability of $70 \mathrm{mD}$. The used core samples were carbonate type from an Iranian carbonate reservoir (limestone and dolomite were about $79 \%$ and $13 \%$, respectively). They were saturated with oil.

\section{Results and discussion}

\subsection{Hydrochloric acid content in the developed scale inhibitor}

In the investigation of the scale inhibitor, the optimum mass concentration of $5 \%$ hydrochloric acid $(\mathrm{HCl})$ solution in the inhibitor was determined by measuring the change in the surface tension on the boundary layer between oil and the aqueous scale inhibitor solution. The used crude oil was an Iranian light type, with a density of $852 \mathrm{~kg} / \mathrm{m}^{3}$ under reservoir conditions and an oil viscosity of $0.89 \mathrm{cP}$ at $80^{\circ} \mathrm{C}$. The content of sulfur in the oil was

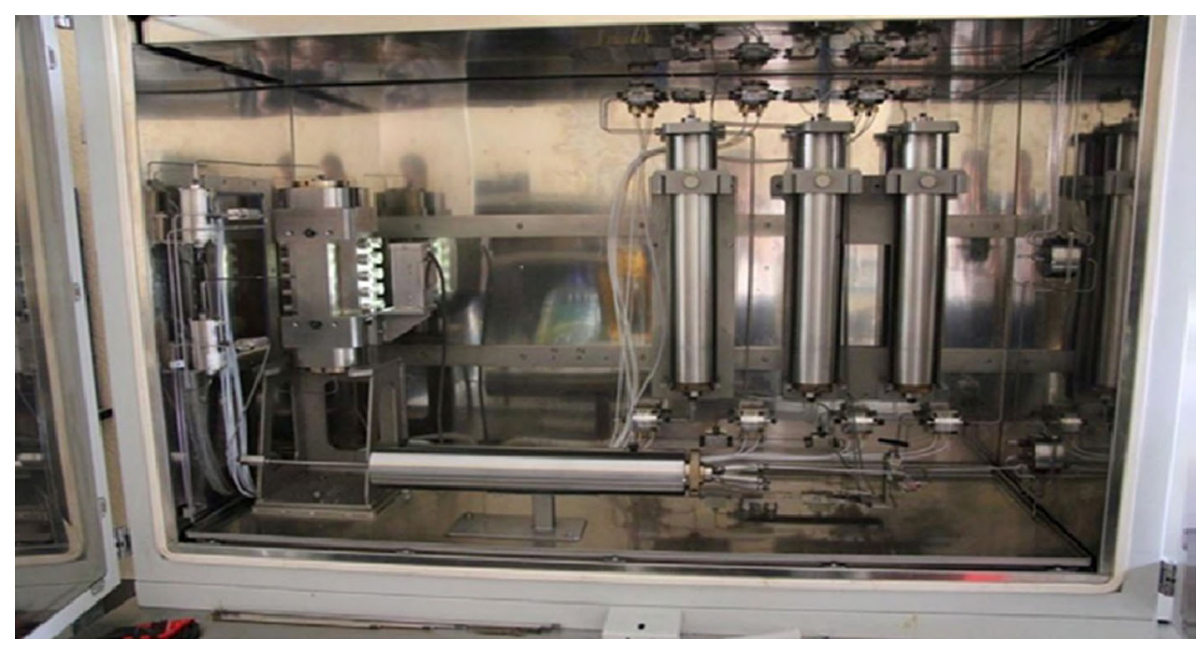

Fig. 1 Apparatus for injecting the inhibitor and water into a core 
about $1.08 \mathrm{wt} \%$. Experimental results of this test are shown in Fig. 2. The figure shows that a significant reduction in the surface tension occurred with an addition of $5 \% \mathrm{HCl}$ solution up to $8 \%$. The surface tension reduced slightly when adding 8-10 mass percent of $5 \% \mathrm{HCl}$ solution, indicating a further increase in the mass fraction of $5 \%$ $\mathrm{HCl}$ solution practically did not reduce this parameter. It can be concluded that the mass percentage of $5 \% \mathrm{HCl}$ solution in the range of $8-10 \%$ is suitable for the preparation of an inhibitor composition for preventing the formation and deposition of $\mathrm{CaCO}_{3}$.

\section{2 $\mathrm{CaCO}_{3}$ scaling inhibition under static conditions}

\subsubsection{Effectiveness of inhibitors and their compatibility with formation waters}

In the laboratory, the protective performance of scale inhibitors was evaluated in synthetic formation water because using synthetic formation water, instead of actual formation water, can improve the reproducibility of test results. The synthetic formation water was prepared based on the chemical compositions of the produced water.

Experimental results of the efficiency of inhibitors are listed in Table 2, which reveals that the developed chemical compositions had the necessary protective effect (effectiveness of more than $85 \%$ ) for calcium carbonate. Inhibitor No. 1 had the highest effectiveness for preventing calcium carbonate precipitation in all formation waters. The difference between inhibitors No. 1 and No. 2 is the change in the mass fraction of inhibitor components. Inhibitor No. 3 is an industrial inhibitor for preventing calcium carbonate formation, which is commonly used in oilfields. Table 2 clearly illustrates that inhibitor No. 3 could prevent the formation of calcium carbonate up to $87 \%$.

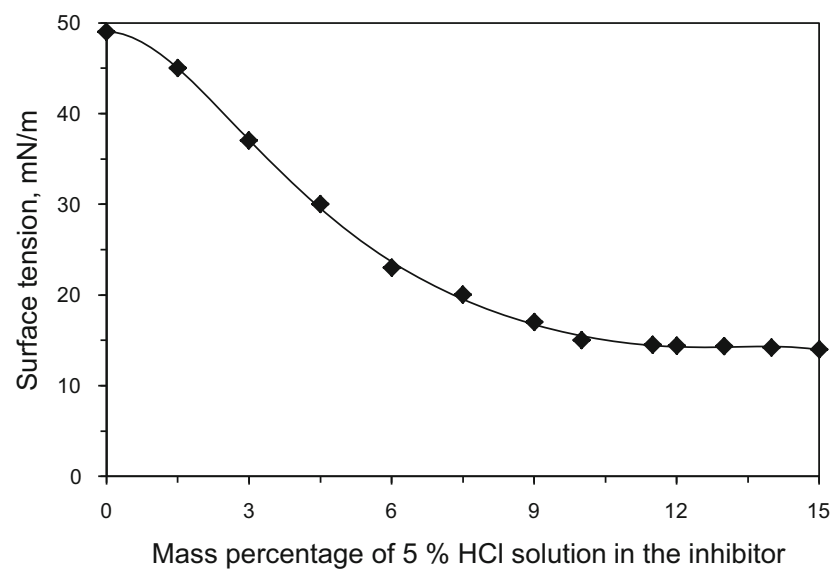

Fig. 2 Surface tension on the boundary layer between oil and the aqueous scale inhibitor solution at different mass concentrations of $5 \% \mathrm{HCl}$ solution in the inhibitor
The scale inhibitor should be fully compatible with formation water without any precipitate formation (Dawe and Zhang 1997). Studies have been conducted to determine the compatibility of scale inhibitors with formation waters. All inhibitors were compatible with the three synthetic formation waters, and the experimental results show that all the above chemical compositions could be prepared with formation waters. In case of formation water containing high concentrations of $\mathrm{Ca}^{2+}$, the scale inhibitor is considered compatible with the formation water if turbidity is not observed within $24 \mathrm{~h}$. In addition, the inhibitor effectiveness largely depends on $\mathrm{Ca}^{2+}$ concentration in formation waters.

\subsubsection{Optical density of the aqueous scale inhibitor solution}

To determine the optical density of the developed aqueous scale inhibitor solution, each tested sample was measured with a photo-electrocalorimeter two or three times, and the arithmetic mean was calculated. From the obtained data, a calibration curve was plotted, where the inhibitor concentration in $\mathrm{mg} / \mathrm{L}$ was plotted on the horizontal axis, and the magnitude of its corresponding optical density on the vertical axis as shown in Fig. 3. The figure displays the high coefficient of determination for the dependency of the optical density on the inhibitor concentration. In this curve, knowing the value of the absorbance, it is possible to find the required scale inhibitor concentration for further development by initiating a new aqueous scale inhibitor solution.

\subsubsection{Effect of the scale inhibitor on induction time of $\mathrm{CaCO}_{3}$ scale formation}

Figure 4 illustrates the curves of light transmission before and after the inhibition treatment of the salt solution with time. In these curves, transmittance (light absorption) was constant with time from the start of the test until inorganic salt is formed. After salt precipitation, the light absorption reduced with time. The period from the beginning until the salt is deposited is called the induction time. This figure indicates that the induction period of $\mathrm{CaCO}_{3}$ crystallization in the supersaturated aqueous solution was increased in the presence of scale inhibitors. As shown in the figure, inhibitor No. 1 had the longest induction period of all the inhibitors.

\subsubsection{Corrosion assessments of scale inhibitors}

Scale inhibitor must have low corrosiveness. The corrosion activity of the used scale inhibitors was evaluated through the mass reduction of reference samples after their immersion in the aqueous scale inhibitor solution. A scale 
Table 2 Effectiveness of scale inhibitors

\begin{tabular}{|c|c|c|c|c|}
\hline \multirow[t]{2}{*}{$\begin{array}{l}\text { Scale inhibitor } \\
\text { number }\end{array}$} & \multirow[t]{2}{*}{ Chemical composition of the scale inhibitor (in mass percent) } & \multicolumn{3}{|c|}{$\begin{array}{l}\text { Scale inhibition efficiency } \\
\text { (in, } 30 \mathrm{mg} / \mathrm{L} \text { of inhibitor), } \%\end{array}$} \\
\hline & & $\begin{array}{l}\text { First } \\
\text { water }\end{array}$ & $\begin{array}{l}\text { Second } \\
\text { water }\end{array}$ & $\begin{array}{l}\text { Third } \\
\text { water }\end{array}$ \\
\hline 1 & $\begin{array}{l}\text { HEDP } 3 \% \text {, ammonium chloride } 4 \% \text {, polyethylene polyamine- } N \text {-methylphosphonic acid } 4 \% \text {, } \\
\text { hydrochloric acid } 10 \% \text {, isopropyl alcohol } 2 \% \text {, water-remaining }\end{array}$ & 91 & 90 & 92 \\
\hline 2 & $\begin{array}{l}\text { HEDP } 1 \% \text {, ammonium chloride } 6 \% \text {, polyethylene polyamine- } N \text {-methylphosphonic acid } 2 \% \text {, } \\
\text { hydrochloric acid } 5 \% \text {, isopropyl alcohol } 6 \% \text {, water-remaining }\end{array}$ & 89 & 87 & 88 \\
\hline 3 & Tested inhibitor, which is based on a composite reagent containing phosphorus & 87 & 85 & 81 \\
\hline
\end{tabular}

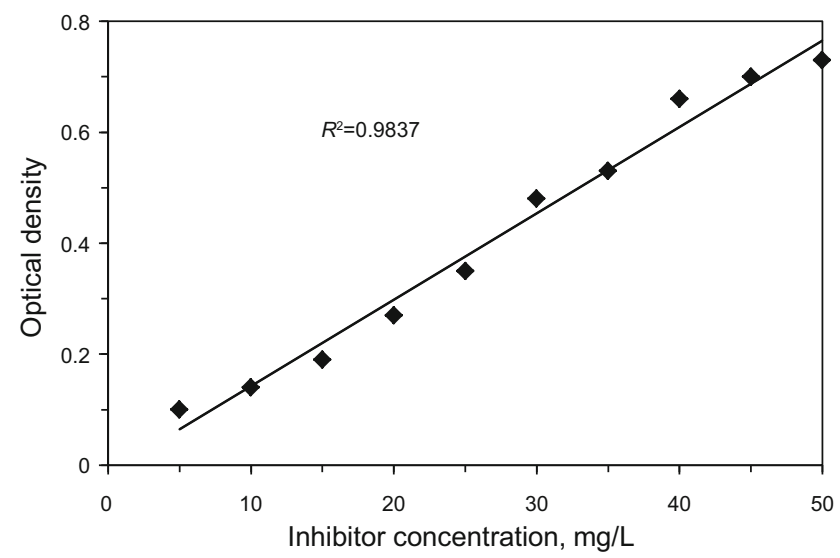

Fig. 3 Change in the optical density of the solution, depending on the inhibitor concentration in water

inhibitor is anticorrosion if pitting does not exist on the surface of the sample and the corrosion rate does not exceed $0.1 \mathrm{~mm} /$ year. Table 3 shows that all the chemical compositions exhibited an allowable corrosion rate (less than $0.1 \mathrm{~mm} /$ year). Therefore, these reagents can be considered as reagents to prevent scaling in wells.

\subsection{Dynamic core testing analysis}

Scale inhibitors should have good adsorption-desorption characteristics, heat resistance, and minimal toxicity (García et al. 2006). The scale inhibitor solutions were injected into the carbonate core samples to study adsorption-desorption properties of the scale inhibitors. The results of this study are shown in Figs. 5 and 6 . Figure 5 shows the relative concentrations of inhibitors depending on the volume of the inhibitor solution injected into the core sample in the adsorption process at $80{ }^{\circ} \mathrm{C}$ and at $8.1 \mathrm{MPa}$. The relative inhibitor concentrations were determined by a ratio of the current (after injecting) to initial (before injecting) concentrations of the inhibitor. Laboratory studies show that the limiting adsorption value (relative concentration of the inhibitor is 1 )

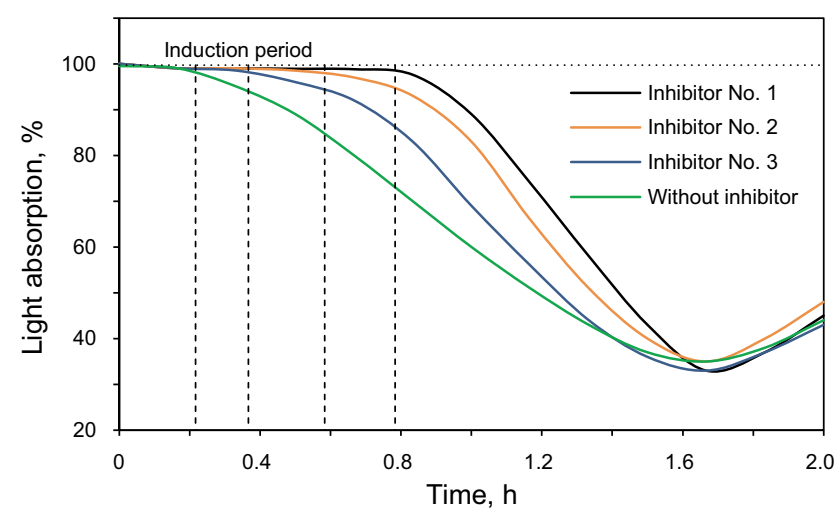

Fig. 4 Dependence of the induction period of calcium carbonate on the curves of light transmission

was achieved at $14 \mathrm{PV}$ inhibitor solution injected for inhibitors No. 1 and No. 2, and at 15 PV for inhibitor No. 3 . Figure 5 illustrates the achievement to the equilibrium adsorption on the surface of porous media under dynamic conditions after injecting the inhibitors into the core samples. As shown in Fig. 5, inhibitor No. 1 had a more uniform curve of changes in the relative concentration than inhibitors No. 2 and No. 3 during the adsorption process.

Once the core was left for $24 \mathrm{~h}$ to attain adsorption equilibrium, the formation water was pumped into the core to displace the inhibitor components. The relative concentrations of inhibitors are shown during the desorption process in Fig. 6. The desorption process can be performed for the optimal concentration of the scale inhibitor in field conditions, when it corresponds to the relative concentration of 0.0001 . Figure 6 illustrates that inhibitor No. 1 could effectively protect the precipitation of $\mathrm{CaCO}_{3}$ in the carbonate core sample before $37 \mathrm{PV}$ water was injected into the core in the desorption process. The values for inhibitors No. 2 and No. 3 were $32 \mathrm{PV}$ and $27 \mathrm{PV}$, respectively. This demonstrates that the developed inhibitor has 1.37 times greater duration of desorption than inhibitor No. 3 .

Data on the removal of considered inhibitor components show that a significant portion of the free inhibitor (non- 
Table 3 Corrosion rates of scale inhibitors

\begin{tabular}{|c|c|c|c|c|c|c|c|}
\hline \multirow{2}{*}{$\begin{array}{l}\text { Scale } \\
\text { inhibitor }\end{array}$} & \multirow{2}{*}{$\begin{array}{l}\text { Test } \\
\text { duration, } \mathrm{h}\end{array}$} & \multicolumn{2}{|l|}{ First water } & \multicolumn{2}{|l|}{ Second water } & \multicolumn{2}{|l|}{ Third water } \\
\hline & & $\begin{array}{l}\text { Mass } \\
\text { reduction, mg }\end{array}$ & $\begin{array}{l}\text { Corrosion } \\
\text { rate, } \mathrm{mm} / \text { year }\end{array}$ & $\begin{array}{l}\text { Mass } \\
\text { reduction, mg }\end{array}$ & $\begin{array}{l}\text { Corrosion } \\
\text { rate, } \mathrm{mm} / \text { year }\end{array}$ & $\begin{array}{l}\text { Mass } \\
\text { reduction, mg }\end{array}$ & $\begin{array}{l}\text { Corrosion } \\
\text { rate, } \mathrm{mm} / \text { year }\end{array}$ \\
\hline 1 & 72 & 1.3 & 0.0404 & 1.5 & 0.0467 & 1.7 & 0.0529 \\
\hline 2 & 72 & 1.7 & 0.0529 & 1.9 & 0.0591 & 2.0 & 0.0622 \\
\hline 3 & 72 & 2.1 & 0.0650 & 2.1 & 0.0653 & 2.2 & 0.0684 \\
\hline
\end{tabular}

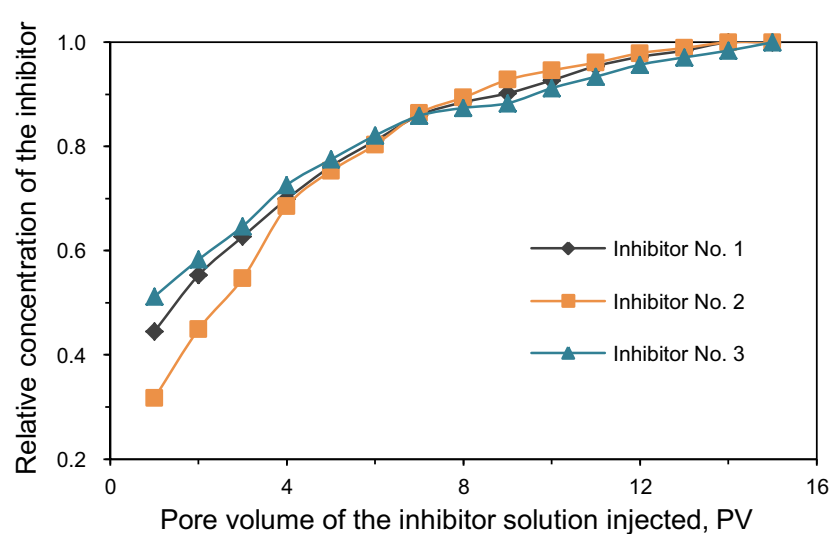

Fig. 5 Change of the inhibitor concentration at the core outlet in the adsorption process

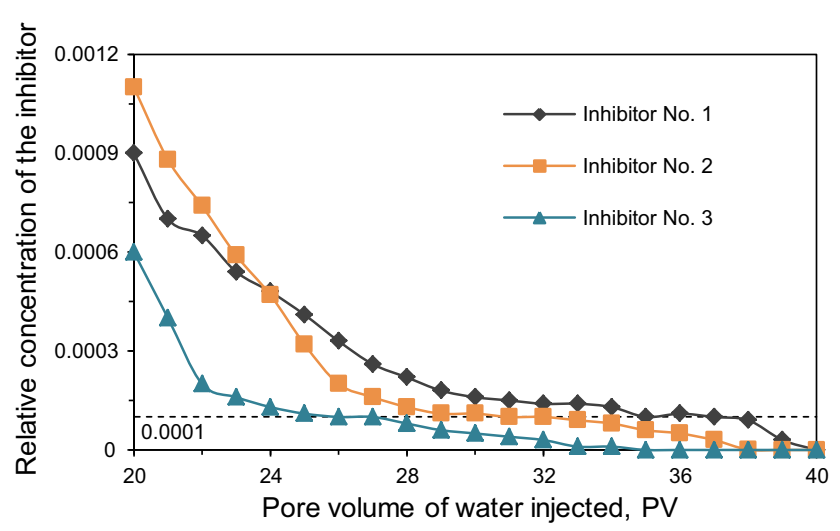

Fig. 6 Change of the inhibitor concentration at the core outlet in the desorption process

adsorbed) passed through the core during pumping the first $2 \mathrm{PV}$ of the inhibitor solution. $\mathrm{HCl}$ solution is necessary to maintain the increased acidity of the medium in the solution. $\mathrm{HCl}$ solution is also capable of changing the wettability of rocks, and clearing the surface of the oil (the core samples were saturated with the oil). This ensures a uniform and more complete adsorption of the scale inhibitor. During the injection of the scale inhibitor solution into the core samples, the presence of $\mathrm{HCl}$ provides an increase in the desorption degree of the inhibitors on the rock surfaces. Thus, the desorption property of the new inhibitor has been investigated by considering the influence of the acidic components of the inhibitor on the rock. The inhibitor components formed a contact layer between the scale inhibitor and mineral surfaces. Owing to this, desorption occurs slowly in reservoir rocks because the inhibitor layer on the rock surface is substantially resistant to leaching. This characteristic of the inhibitor leads to the fact that the period of desorption is increased, and from this, it can be concluded that the effectiveness of the scale inhibitor is increased. Thus, the developed inhibitor effectively protects the downhole equipment and reservoir from deposition of $\mathrm{CaCO}_{3}$ for a long time.

\section{Conclusions}

(1) Comprehensive experimental work was carried out to study $\mathrm{CaCO}_{3}$ scaling inhibition by the developed inhibitor in production equipment and carbonate oil reservoirs. Based on the experimental results, it can be concluded that the new scale inhibitor can be used in oilfields.

(2) The mass fractions of the components in the aqueous scale inhibitor solution, at which the developed scale inhibitor was effective for preventing scale formation of $\mathrm{CaCO}_{3}$ up to $92 \%$, were determined.

(3) Surface tension between the oil and the aqueous scale inhibitor solution was reduced by increasing the mass percentage of $5 \% \mathrm{HCl}$ solution in the inhibitor until its value has reached $10 \%$, after which the surface tension remained constant.

(4) The induction period of $\mathrm{CaCO}_{3}$ scale formation in the supersaturated formation brine water increased in the presence of the scale inhibitor. The corrosion rate of the developed scale inhibitor was in the range of 0.04-0.053 mm/year (less than the maximum allowable corrosion rate- $0.1 \mathrm{~mm} /$ year).

(5) Adsorption of the developed inhibitor onto the formation rock occurred more rapidly than the used industrial inhibitor. Also, the new inhibitor was more slowly and in larger pore volume of injected synthetic formation water desorbed in comparison with the tested industrial inhibitor. 
Open Access This article is distributed under the terms of the Creative Commons Attribution 4.0 International License (http://crea tivecommons.org/licenses/by/4.0/), which permits unrestricted use, distribution, and reproduction in any medium, provided you give appropriate credit to the original author(s) and the source, provide a link to the Creative Commons license, and indicate if changes were made.

\section{References}

Al-Tammar JI, Bonis M, Salim Y, et al. Saudi Aramco downhole corrosion/scaling operational experience and challenges in HPHT gas condensate producers. In: SPE international oilfield corrosion conference and exhibition, 12-13 May, Aberdeen, Scotland; 2014. doi:10.2118/169618-MS.

Awan MA, Al-Khaledi SM. Chemical treatments practices and philosophies in oilfields. In: SPE international oilfield corrosion conference and exhibition, 12-13 May, Aberdeen, Scotland; 2014. doi:10.2118/169626-MS.

Bezerra MCM, Rosario FF, Rosa KRSA. Scale management in deep and ultradeep water fields. In: OTC Brasil, 29-31 Oct, Rio de Janeiro, Brazil; 2013. doi:10.4043/24508-MS.

Chen T, Neville A, Yuan M. Calcium carbonate scale formationassessing the initial stages of precipitation and deposition. J Pet Sci Eng. 2005;46(3):185-94. doi:10.1016/j.petrol.2004.12.004.

Chen T, Chen P, Montgomerie H, et al. Scale squeeze treatments in short perforation and high water production ESP wellsapplication of oilfield scale management toolbox. In: International petroleum technology conference, 26-28 March, Beijing, China; 2013. doi:10.2523/IPTC-16844-MS.

Dawe RA, Zhang Y. Kinetics of calcium carbonate scaling using observations from glass micromodels. J Pet Sci Eng. 1997;18(3-4):179-87. doi:10.1016/S0920-4105(97)00017-X.

Demadis KD, Stathoulopoulou A, Ketsetzi A. Inhibition and control of colloidal silica: can chemical additives untie the "Gordian Knot" of scale formation?. In: Corrosion 2007, 11-15 March, Nashville, Tennessee; 2007. NACE 7058

Drela I, Falewicz P, Kuczkowska S. New rapid test for evaluation of scale inhibitors. Water Res. 1998;32(10):3188-91. doi:10.1016/ S0043-1354(98)00066-9.

El-Said M, Ramzi M, Abdel-Moghny T. Analysis of oilfield waters by ion chromatography to determine the composition of scale deposition. Desalination. 2009;249(2):748-56. doi:10.1016/j. desal.2008.12.061.

Fan C, Kan AT, Zhang P, et al. Scale prediction and inhibition for oil and gas production at high temperature/high pressure. SPE J. 2012;17(2):379-92. doi:10.2118/130690-PA.

García AV, Thomsen K, Stenby EH. Prediction of mineral scale formation in geothermal and oilfield operations using the Extended UNIQUAC model: Part II. Carbonate-scaling minerals. Geothermics. 2006;35(3):239-84. doi:10.1016/j.geother mics.2006.03.001.

Kelland MA. Effect of various cations on the formation of calcium carbonate and barium sulfate scale with and without scale inhibitors. Ind Eng Chem Res. 2011;50(9):5852-61. doi:10. 1021/ie2003494.

Khormali A, Petrakov D. Scale inhibition and its effects on the demulsification and corrosion inhibition. IJPGE. 2014;2(1):22-33.

Kumar T, Vishwanatham S, Kundu SS. A laboratory study on pteroylL-glutamic acid as a scale prevention inhibitor of calcium carbonate in aqueous solution of synthetic produced water. J Pet Sci Eng. 2010;71(1-2):1-7. doi:10.1016/j.petrol.2009.11.014.

Lakshmi DS, Senthilmurugan B, Drioli E, et al. Application of ionic liquid polymeric microsphere in oil field scale control process. J Pet Sci Eng. 2013;112:69-77. doi:10.1016/j.petrol.2013.09.011.

Levanyuk OV, Overin AM, Sadykov A, et al. A 3-year results of application a combined scale inhibition and hydraulic fracturing treatments using a novel hydraulic fracturing fluid, Russia. In: SPE international conference on oilfield scale, 30-31 May, Aberdeen, Scotland; 2012. doi:10.2118/155243-MS.

MacAdam J, Parsons SA. Calcium carbonate scale formation and control. Rev Environ Sci Bio/Technol. 2004;3(2):159-69. doi:10.1007/s11157-004-3849-1.

Mackay EJ. Scale inhibitor application in injection wells to protect against damage to production wells: when does it work? In: SPE European formation damage conference, 25-27 May, Scheveningen, The Netherlands; 2005. doi:10.2118/95022-MS.

Matty JM, Tomson MB. Effect of multiple precipitation inhibitors on calcium carbonate nucleation. Appl Geochem. 1988;3(5): 549-56. doi:10.1016/0883-2927(88)90026-1.

Mavredaki E, Neville A. Prediction and evaluation of calcium carbonate deposition at surfaces. In: SPE international oilfield scale conference and exhibition, 14-15 May, Aberdeen, Scotland; 2014. doi:10.2118/169796-MS.

Moghadasi J, Müller-Steinhagen H, Jamialahmadi M, et al. Model study on the kinetics of oil field formation damage due to salt precipitation from injection. $J$ Pet Sci Eng. 2004;43(3-4):201-17. doi:10.1016/j.petrol.2004.02.014.

Osokogwu U, Oghenekaro E. Evaluation of corrosion inhibitors effectiveness in oil field production operation. IJSTR. 2012;1(4):19-23.

Ostroff AG. Comparison of some formation water classification systems. AAPG Bull. 1967;51(3):404-16.

Poynton N, Miller A, Konyukhov D, et al. Squeezing scale inhibitors to protect electric submersible pumps in highly fractured, calcium carbonate scaling reservoirs. In: SPE Russian oil and gas technical conference and exhibition, 28-30 Oct, Moscow, Russia; 2008. doi:10.2118/115195-MS.

Tomson MB, Fu G, Watson MA, et al. Mechanisms of mineral scale inhibition. SPE Prod Facil. 2003;18(3):192-99. doi:10.2118/ 84958-PA.

Tortolano C, Chen T, Chen P, et al. Mechanisms, new test methodology and environmentally acceptable inhibitors for codeposition of zinc sulfide and calcium carbonate scales for high temperature application. In: SPE international oilfield scale conference and exhibition, 14-15 May, Aberdeen, Scotland; 2014. doi:10.2118/169810-MS. 